\title{
Kind Properties and the Metaphysics of Perception: Towards Impure Relationalism
}

\author{
Draft (updated 29/10/14) \\ Conditionally accepted for publication in J. Lyons and I. Reiland, eds. Is Perceptual \\ Experience Disunified? Special Issue of Pacific Philosophical Quarterly \\ Dan Cavedon-Taylor \\ Centre for Philosophical Psychology \\ University of Antwerp \\ daniel.cavedon-taylor@uantwerpen.be
}

\begin{abstract}
A central debate in contemporary philosophy of perception is between those who believe that perceptual experience is a detection relation of sensory awareness (naïve realists) and those who hold that it is representational mental state akin to belief (representationalists). Another key debate is between those who think we can perceptually experience natural or artifactual kind properties, e.g., 'being a tomato', 'being a doorknob', etc. and those who think we cannot. Current consensus is that these debates are entirely unrelated; in particular, the possibility of perceiving natural or artifactual kinds is said to have no consequences for whether perception is relational or representational. This consensus is wrong, however. At best, naïve realism only vindicates the possibility of perceptually experiencing natural or artifactual kind properties by making substantial assumptions about the metaphysics of such properties, something the representationalist avoids. At worst, naïve realism is incompatible with the possibility of perceptually experiencing natural and artifactual kinds. The solution for naïve realists who do wish to accommodate such a possibility is to embrace a disunified metaphysics of perception, one that combines both relational and representational events. Call such a view 'impure relationalism.'
\end{abstract}

This paper centres on the following thesis:

Kind Perception (KP):

Subjects can perceptually experience the kind properties of objects

Someone who affirms KP rejects the so-called 'sparse', or 'thin', or 'conservative' view of the range of properties one can perceive. According to deniers of KP, objects cannot look to be the kinds of things they are. By way of illustration, suppose you are looking at a tomato. The tomato may look red to you. Colour properties, that is, are among the properties one can perceive. The tomato may also look round or bulgy to you. Shape properties, similarly, are among those properties one can perceive. Question: does the tomato look to be the very thing 
it is: a tomato? Those who affirm KP say "yes" while those who deny $\mathbf{K P}$ say "no." For the latter group, tomatoes look red and round, but not much else. For both groups, 'being a tomato' is a property that you may judge a tomato to possess. Indeed, for those who affirm $\mathbf{K P}$, the rapidity with which mature perceivers judge an object to be a tomato may be taken to supply a reason for thinking that such subjects first perceive that object to be a tomato.

KP does not require that subjects always experience objects to be the kinds of things they are, just that this is sometimes the case. An argument for KP one can find in the relevant literature is that KP is mandatory. Berit Brogaard (2013: 37), for instance, attributes this argument to Tim Bayne (2009): one cannot help but see an object to be a tomato, a doorknob, a lemon, a spoon etc. For my purposes, no mandatoriness is built into KP. ${ }^{1}$

Debate surrounding KP does not concern epistemic or comparative looks. Those who defend KP and those who demur agree that someone reporting "That looks to be a tomato" may be asserting the possibility that the demonstrated object is a particular kind of thing; namely, a tomato. Perhaps the speaker may do so on the basis of perceptually experiencing the object's colour and shape, in combination with background beliefs associating these properties with the kind property 'being a tomato.' All this may be agreed upon between defenders and deniers of KP. This is a matter of epistemic looks.

Moreover, someone reporting "That looks to be a tomato" may be asserting belief in visual similarity between the demonstrated object, an expertly-fashioned wax replica, say, and tomatoes. This visual similarity will likely reduce to colours and shapes that are shared by the demonstrated object and a certain class of objects; namely, tomatoes. Again, so much may be agreed upon between defenders and deniers of KP. This is the matter of comparative looks.

What defenders of KP assert is that "That looks to be a tomato" sometimes expresses neither a judgement of probability, nor one of similarity. Instead, it may directly express the speaker's perceptual experience itself, no less than expressions like "That looks red" or "That looks round." This is a matter of so-called phenomenal looks. The claim that objects phenomenally look to be the kinds of things they are is where deniers of $\mathbf{K P}$ jump ship. ${ }^{2}$

KP has become a hotly-debated topic in contemporary philosophy of perception. My aim is not to directly address the question of whether $\mathbf{K P}$ is true. Instead, I will take KP for granted. My purpose in doing so is to examine the following question: what theory, or theories, concerning the metaphysics of perceptual experience ought we defend, if $\mathbf{K P}$ is true? Similarly, what theory, or theories, concerning the metaphysics of perception, ought we to reject, if $\mathbf{K P}$ is true? It is often assumed that the truth value of KP has interesting

1 Throughout, I shall understand 'perceptual experience' in a narrow way, as picking out those mental states that have a sensory phenomenal character. There may be doxastic states which are closely related to perceptual experience such as, e.g., perceptual beliefs, perceptual judgements and maybe perceptual seemings too. For my purposes, these states should be taken to be post-experiential. Depending on one's view, the latter states may not have phenomenal character, or they may have cognitive phenomenology, or they may have a quasi-sensory/quasi-cognitive phenomenology (see Reiland 2014 for the options).

2 For discussion of the senses of 'looks', see Chisholm (1957), Jackson (1977), and more recently, Brogaard (forthcoming). Lyons (2009) claims that we should recognise a further, epistemically significant, but non-experiential sense of 'looks.' 
consequences for theories of perceptual justification. For instance, it is sometimes claimed that if KP is true, then perception immediately justifies a greater number of beliefs than if it were false: if an object can look to be a tomato, then we can have immediate justification for believing that object to be a tomato, whereas this belief can't be immediately justified by perception if the object in question only looks red and round, say (Siegel 2006: section 2; though see Silins 2013 for dissent).

By contrast, the prevailing consensus is that $\mathbf{K P}$ entails nothing of importance for the correct account of the metaphysics of perception. I believe that this consensus is wrong. My first aim in this paper is to show that KP favours representationalism over naïve realism, since it is very unlikely that the naïve realist can accommodate KP. If that is right, then one question we might ask is what should a naïve realist do, if they find KP attractive? My second aim is to develop an answer to this question. The answer I defend is that naïve realists should disunify their metaphysics of perception by admitting that the perceiving of an object, as the kind of thing it is, involves a representational event.

Naïve realists are no strangers to disunifying their metaphysics of perception, since affirming naïve realism naturally leads one to affirm disjunctivism (Martin 2004; Travis 2004; Fish 2009). Disjunctivists hold that the perceiving of a tomato is a mental event fundamentally distinct from that of hallucinating a tomato. Still, while naïve realists who affirm disjunctivism give a disunified account of the mental event constitutive of (i) perceiving a tomato and (ii) hallucinating one, they give a unitary account of the mental events constitutive of each putatively distinct event. My suggestion is that naïve realists may accommodate KP, if they so wish, by defending a more radically disunified metaphysics of perception. In particular, they ought to hold that the event involved in (i), the veridical perceiving of a tomato, qua the kind of object it is, factorises into two fundamentally distinct events: a relational event of perceptual detection and a non-relational event of perceptual representation.

In section I, I lay out the debate between naïve realism and representationalism. In section II, I discuss the claim that KP is neutral between the two theories. In section III, I present considerations that challenge this claim. In section IV, I sketch the metaphysics of perception that I believe naïve realists ought to affirm, if they wish to affirm KP, a view I call 'impure representationalism.' Section V concludes with a discussion of the dialectical situation regarding KP itself.

\section{I - Naïve realism vs Representationalism}

There are diverse desiderata that we want our theories of the metaphysics of perception to vindicate. Some of these are phenomenological, while some are epistemological. Other desiderata are metaphysical, and others, further still, are semantic. Moreover, weighing the importance of each desideratum is a complex task. So much is familiar from the history of the philosophy of perception.

But suppose we focus on KP alone. What theories would we now defend and reject? Or, posed in the form of a conditional: if, in choosing between theories of the metaphysics of perception, we take KP to be a desideratum, what views should we defend and reject, all other considerations being equal? 
By a 'metaphysics' of perceptual experience, I refer to the issue of what is sometimes called the nature of perceptual experience. With this in mind, allow me to narrow the above question further still by supposing we were forced to choose between naïve realism and representationalism. This further qualification is not arbitrary. These two theories fight for dominance in contemporary philosophical debate about the metaphysics of perception. Sensedatum and adverbialist theories, while not without capable defenders, have largely fallen by the way-side.

According to naïve realism, veridical perception is a relational mental event. Variously called 'acquaintance', 'awareness', 'detection', 'presentation', and more besides, this sensory relation is typically taken to be brute and unanalysable. ${ }^{3}$ Crucially, because naïve realists understand veridical perception to be a relation, with the perceiving subject and concrete particulars (along with their properties) as the relata, such philosophers must give a different account of the mental event constitutive of hallucinating, e.g., a red tomato. In the latter case, there is no instance of redness, and no particular tomato, to which the subject is sensorily related. So, hallucinating a tomato must be an entirely different mental event from the perceiving of a tomato. This is not to say that perceiving a red tomato and hallucinating one are mental events that have nothing in common (pace Putnam 1999: 152). Both events may rationalise the subject's belief that there is a tomato before them and both events may cause action, in combination with the agent's motivational set. Moreover, the two events are indiscriminable, something that the naïve realist may exploit to explain the rational and action-guiding commonalities of perception and hallucination (Martin 2004: 67). Thus, adopting naïve realism naturally leads one to deny a so-called 'common-factor account' of the mental event constitutive of (i) perceiving a red tomato and (ii) hallucinating a red tomato, but without having to deny that such events may have commonalities. ${ }^{4}$

According to representationalism, veridical perception is to be analysed as a representational mental event, akin with, say, belief. This contrasts with the naïve realist's metaphysics of perception insofar as 'representation' is standardly analysed in non-relational terms, i.e. as failing to licence existential generalisation. A newspaper report, or a representational painting, say, does not entail the existence of the objects, events, etc. represented. On this account, to veridically perceive a tomato, in the visual modality, is to token an event of visually 'attributing' or 'predicating' properties (e.g., redness, roundness, etc.) to an object (e.g., a tomato). Those properties are represented as instantiated in the scene before. Crucially, on this view, veridical perceptual experience is not to be analysed as the bearing of a relation to actual instantiations of properties by objects. With 'representation' understood in this way, representationalists are at liberty to give a common-factor account of the mental event constitutive of perceiving and hallucinating a red tomato. Whether or not the tomato is present, one's visual experience is an event of visually representing there to be a red, round, object before one.

3 An exception here is the enactive realism defended by Noë (2005). According to Noë, the sensory relation constitutive of perception is a naïve-realist-like one, but it is further analysed in terms of the perceiver's sensorimotor knowledge, i.e. first-hand, practical knowledge of how sensory stimulation varies with movements of one's body.

$4 \quad$ A notable exception is Johnston's (2004) naïve realism, which he claims is a nondisjunctive, common-factory theory of perception and hallucination. Although, as Fish (2010: 98) points out, Johnston's view may actually be a version of 'positive' disjunctivism. 
Debate between naïve realism and representationalism can be framed in a number of ways. I have focussed on their disagreement over whether the event constitutive of (veridical) perception is a relation to objects and their properties, or whether it a non-relational event that represents such items. I have also focussed on the consequences this has for each theory in terms of their subsequent denial or affirmation of that event being a common-factor across both perception and hallucination. I take this relational/representational disagreement, so framed, to be what essentially divides the two theories. But there are various ways in which each theory can be further developed. For instance, naïve realists disagree on such matters as the nature of the mental event constitutive of hallucinating a tomato (for an overview, see Byrne and Logue (2008)) and on the possibility of including a third relatum, in addition to the perceiving subject and concrete particulars (along with their properties), to fully account for perception's phenomenal character (Brewer 2011; Campbell 2009; Fish 2009: 75, as we shall see, includes several relata). Representationalists, by contrast, disagree over the nature of representational content: its semantic structure, its acquisition and its relation to phenomenal character, among other things.

There are various consequences that follow from this fundamental disagreement between the two positions over whether perceiving is relational or representational. For instance, the naïve realist should hold that, strictly speaking, perception is never erroneous. As Charles Travis puts it:

Perception, as such, simply places our surroundings in view; affords us awareness of them... Perception cannot present things as being other than they are. It cannot present some way some things are, not as what is so. That would not be mere confrontation [with objects and their properties]. (2004: 65)

According to Travis, as I read him, only veridical perceptual experiences qualify as perceptual; hallucinations do not. Indeed, the qualifier 'veridical' is thereby made redundant. For the naïve realist who adopts disjunctivism, there is perceptual experience on the one hand, and there is an event of an entirely different nature on the other: hallucination, which, for reasons the disjunctivist must explain, mistakenly passes in introspection for perceptual experience.

According to the representationalist, by contrast, 'perceptual experience' is a neutral term, ascriptions of which leave open whether the subject is perceiving or hallucinating. If the subject is hallucinating, then the experience is in error: what it represents to be present is not. In such cases, there is a fact of mismatch between perceptual experience and world, one that does not have a place within the naïve realist framework, where perceptual experience is analysed as a relation.

A further consequence of whether one understands perception to be relational or representational is the matter of whether concepts may be involved in perception. If perception is a relation to objects and property instances, then concepts do not figure in perception; rather, objects and property instances do. This is not to rule out the possibility that for any perceptual experience there is an associated proposition that describes how the world looks to the subject (see Siegel 2010; Schellenberg 2011; Logue forthcoming).

On representationalism, perceptual experiences are not just candidates for having associated propositions; rather, they are candidates for having propositions as their constituents, though there are representationalists who claim that some properties, e.g., colours, are such that their 
representation is non-propositional in nature (Tye 1995). Either way, the content of a perceptual experience is said to specify 'accuracy conditions' for that experience. Again, as a consequence of claiming that perceptual experience is a relation, talk of 'accuracy conditions' is not something that finds a place within the naïve realist framework.

\section{II - Kind Perception and Naïve realism vs Representationalism pt1}

Let us return to the thesis that is the central concern of this paper:

Kind Perception (KP):

Subjects can perceptually experience the kind properties of objects

Nearly every discussion of KP takes place within a representationalist framework. To that extent, KP is typically investigated indirectly, by way of investigating whether the following is true:

\section{Representationalist Kind Perception (RepKP):}

Subjects can visually represent kind properties to be instantiated by objects

As it is sometimes put, ${ }^{\text {Rep }} \mathbf{K P}$ affirms that natural and artifactual kind properties are among the properties admissible in perceptual content.

Now, insofar as debate over KP typically proceeds in this manner, i.e. by way of debate over

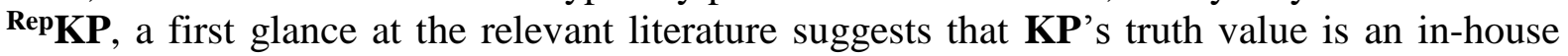
issue for representationalists alone to settle.

Interpreting the dialectical situation in this way is typically warned against. Philosophers who discuss KP's truth value by way of discussing RepKP's truth value often state that adopting the representationalist framework here is not mandatory. Indeed, the consensus is that $\mathbf{K P}$ can be framed in non-representationalist terms friendlier to the naïve realist.

For instance, in answering the question 'which properties are represented in perceptual experience?', Susanna Siegel affirms RepKP, arguing that kind properties (and a great deal many others) are perceptually represented. But Siegel considers what one would say if one denies that perception is representational, as the naïve realist does. Here is her response:

An analogous question would then arise: namely, which properties are such that their property instances can (partially) constitute experiences? (2006: 483 n.3) 
Siegel's talk of property instances that can (partially) 'constitute' perceptual experiences chimes with the naïve realist's conception of perception as a detection relation, and with the idea that property instances themselves are (one of) perception's relata.

In discussing Siegel's preferred method for defending RepKP, James Genone writes:

Instead of asking whether kind properties... are represented in visual perception, for example, she could have asked instead whether we are ever visually aware of kind properties... As is apparent from many of her examples, the method of phenomenal contrast, which Siegel introduces as a way of deciding what the contents of perception are, can be applied just as easily to the question of what we are visually aware of as to the question of what we visually represent. (2011: np)

This talk of properties of which one is 'visually aware' signals that Genone takes there to be a naïve realist analogue of Rep $\mathbf{K P}$, on the assumption that 'visual awareness' is a synonym for 'acquaintance', 'detection', 'property-presentation', etc.

John Bengson, who interprets the debate about KP as one of perception's 'richness' makes the same point:

We can investigate the question of richness with equal clarity, without invoking content, or predication, by focusing on property-presentation. Such an approach might still, if desired, employ Siegel's method of phenomenal contrast, to which the invocation of content is inessential... Indeed, by focusing on property-presentation, nothing is sacrificed. (2013: 804-5)

Bengson later claims:

[T]he debate over richness looks to be smoothly captured in terms of propertypresentation. (2013: 805)

In his recent book, Bence Nanay echoes the central idea:

I will ... [be] specifying what properties are represented in perception: what properties perceptual representations attribute to objects. The anti-representationalist can read this discussion as being about what properties perceptual states "present" or "are sensitive to" or "track." ... The question that I frame as "What properties are represented in perception?" could be framed for these anti-representationalists as "What properties of perceived objects are we perceptually related to?" (2013: 36)

Siegel, Genone, Bengson and Nanay are undeniably right about this: since the naïve realist understands perceptual experience to be a relation, they cannot talk of properties represented by perceptual experience, but will instead talk of properties detected by perceptual experience (or talk of properties of which the subject is 'aware', or properties which the subject is 'acquainted with', or properties 'present in' experience, etc.). Heather Logue (2013), Nicholas Silins (2013) and Indrek Reiland (2014) also engage the debate about KP while 
suggesting that one can remain neutral on the matter of whether representationalism or naïve realism is true. ${ }^{5}$

Accordingly, the dialectical situation appears to be as follows: while naïve realists cannot investigate whether KP is true via investigating whether Rep KP is true, they can join the debate by investigating something like the following instead:

\section{Naïve Realist Kind Perception ( $\left.{ }^{\mathrm{Nr} K P}\right)$ :}

Subjects can visually detect the kind properties of objects

Now, the claim that naïve realists can debate $\mathbf{K P}$ via ${ }^{\mathrm{Nr}} \mathbf{K P}$, rather than via ${ }^{\text {Rep }} \mathbf{K P}$, does not, by itself, say very much at all. The claim echoed by the above philosophers is presumably

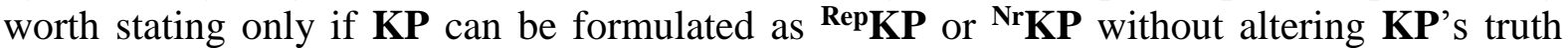
value. That is, I take it that the above philosophers intend to convey that whether one is a representationalist or naïve realist does not matter as far as KP is concerned. The difference between property representational and property detection is immaterial for this debate. And so, while the truth of KP may have consequences for the epistemology of perception, it is said to have no consequences for perception's metaphysics.

\section{III - Kind Perception and Naïve realism vs Representationalism pt2}

The claim that KP has no consequences for perception's metaphysics, while widely endorsed, is highly questionable. Reflecting on the key differences in how representationalists and naïve realists analyse property perception ought to force a rethinking of this issue.

To start things off, it will be helpful to adopt some terminology of Matthew Kennedy's (2009): representationalism endorses, while naïve realism denies separatism about perceptual experience. On representationalism, objects and their properties are entirely separate from perceptual experiences. ${ }^{6}$ On naïve realism, with perceptual understood as a relation, such items are perception's constituents. Representationalism's commitment to separatism, though not always put in Kennedy's terminology, lurks in the background of many objections to the theory. Indeed, Kennedy's claim is that separatism is phenomenologically problematic. But, as we shall see, endorsing separatism is precisely what grants the representationalist a relatively easy route to affirming KP. By contrast, it is the naïve realist's denial of separatism that renders problematic their accommodating of $\mathbf{K P}$.

5 Reiland (personal communication) informs me he is more in sympathy with my claim, developed below, that naïve realism and KP are at odds than his (2014) indicates.

6 This is true even on externalist-representationalist theories which invoke a so-called 'tracking' psychophysics (Tye 1995). On that view, perceptual experiences and ordinary objects are distinct, albeit causally connected when veridical. 
Let us return to naïve realism and focus on the perception of natural kinds. An initial observation is that a positive answer to ${ }^{\mathbf{N r}} \mathbf{K P}$ turns is it being the case that natural kind properties are such that their instances are candidates for perceptual detection. So much is trivially necessary for ${ }^{\mathrm{Nr}} \mathbf{K P}$ to be true. But once this has been noticed, one should immediately have doubts that instances of natural kinds are such candidates. After all, the standard account of such properties appears to hold that they are definitely not candidates for being perceptually detected. For instance, say we accepted an essentialist theory of natural kinds, along Putnamian-Kripkean lines (see Putnam 1973 and Kripke 1972). Then, the properties 'being a tomato' or 'being water', say, would be so-called hidden essences. Such properties would be intrinsic, on this account, but they would not be among those intrinsic properties to which a subject can be related perceptually.

By way of sharpening the relevant considerations, consider the natural kind property 'being water.' Suppose that this property is instantiated by the liquid in the glass on the table before you. If instances of this property-type are to be analysed as a liquid's possession of a certain molecular structure, i.e. $\mathrm{H}_{2} \mathrm{O}$, then, in looking at the glass of liquid, one must conclude that one is unable to perceptually detect that molecular structure; that is, one cannot perceptually detect the natural kind property of the liquid in the glass. After all, by looking at the glass, in such conditions, one cannot make out the liquid's molecules.

One might object to this line of argument on the grounds that scientists can be perceptually related to hidden essences via the use of measuring tools and instruments, such as electron microscopes, say. Even granting that such instruments enhance our visual capacities, defenders of KP would want to insist that the liquid in the glass may look to you to be water in the everyday circumstances mentioned above, when the glass of water is on your kitchen table, and not in the lab (though see Lyons 2005 for dissent on the matter of water being perceptually represented).

Or consider a tomato. On an essentialist account, what it is for an object to be a tomato is likely to be a matter of its instantiating a particular genomic structure. But instances of such a type are, again, not candidates for being perceptually detected. Even if one disagrees, on the grounds that such a structure can be perceptually detected via measuring instruments, the general point stands: such a structure is not a candidate for being perceptually detected in situations in which defenders of KP would likely affirm that tomatoes look to be tomatoes, e.g., when one is browsing the supermarket's fruit and vegetable aisle.

If this is right, then it presents a challenge for ${ }^{\mathrm{Nr}} \mathbf{K P}$ by putting into doubt something on which ${ }^{N r}$ KP's truth turns: the possibility of perceptually detecting kinds. I have focussed on natural kinds, rather than artifactual ones. But the situation the naïve realist finds themselves in is no better, and is indeed far worse, when we consider the latter, e.g., 'being a doorknob', 'being a table', 'being a guitar', etc.

It is widely held that artifactual kind membership is not determined by anything analogous to the intrinsic 'essences' one might take to be constitutive of natural kinds (Wiggins 2001: 87). Instead, artifact kinds are typically identified with makers' intended function(s), perhaps along with the socio-cultural context in which those intentions arise and are fulfilled. Artifactual kinds, that is, are plausibly regarded as complexes of extrinsic, relational properties. Here is Paul Bloom: 
Natural kinds are understood in terms of internal essences; artifacts are thought of in terms of considerations such as creator's intent, characteristic function, and the social and cultural context of the artifact's creation and use. (2007: 154)

There are further issues to be settled about the nature of the relevant intention, how 'characteristic function' ought to be understood, and so on. But this basic difference between natural and artifactual kinds has many consequences. For instance, what constitutes kind membership in the latter case is likely to vary across time and socio-cultural context (Thomasson 2003: 602). Presumably this is not so for natural kinds.

Suppose we accept that ordinary objects like doorknobs, tables and guitars, say, have no intrinsic essence. Then, the challenge for ${ }^{\mathrm{Nr}} \mathbf{K P}$ regarding 'hiddenness' raises its head again, but for different reasons. As a prelude to the worry, we can note that, within the naïve realist framework, some extrinsic properties are unobjectionable candidates for perceptual detection. There appears no difficulty in supposing that the property 'being to the left of $\mathrm{O}$ ', where $\mathrm{O}$ is a variable for an object, could be perceptually detected, perhaps by virtue of the contribution of visual attention, say. Now, are the extrinsic properties that constitute artifactual kinds like this? Plainly not. In looking at a doorknob, the relevant properties that make it a doorknob are such things as: the property of having been made by a creator with such-and-such intentions, the property of having such-and-such a function, the property of having been made in suchand-such a social/cultural context, etc. These are not properties that one can be perceptually related to. After all, these properties are, themselves, relations to a particular person, a function, and a context (likely, a collection of conventions). Crucially, these constituents of the relevant relations are not items to which we are perceptually related when looking at doorknobs. So, due to their relational nature, we should think that artifactual kinds are no less 'hidden' than are natural kinds, at least on a naïve realist framework. Indeed, it is telling that defenders of naïve realism typically frame their thesis in terms of the detection of intrinsic properties alone, to the exclusion of relational ones. Consider Campbell's oft-quoted claim that, according to naïve realism:

[T] he phenomenal character of your experience, as you look around the room, is constituted by the actual room itself: which particular objects are there, their intrinsic properties such as colour and shape. (2002: 116, emphasis my own)

But then what of relational, extrinsic properties, e.g., the property of being a car, a football, a computer, etc.? These properties, along with natural kinds, fall within the scope of $\mathbf{K P}$ and so they fall within the scope of ${ }^{N r} \mathbf{K P}$. But if the naïve realist cannot accommodate the perception of such complexes of relational properties, then they cannot accommodate the perception of artifact properties, and so they cannot make good on $\mathbf{K P}$ or ${ }^{\mathrm{Nr}} \mathbf{K P}$.

Now, I do not wish to be dogmatic about these negative conclusions. There might be theories of natural and artifactual kinds on which such properties are candidates for perceptual detection. But then naïve realists would have to commit to such theories in order to vindicate ${ }^{N r}$ KP. Not only is this a high theoretical cost, but it is quite unclear what such a theory of kinds would look like.

Granted, the metaphysics of natural and artifactual kinds are much more complex than I have done justice to here. All I have flagged is that a quick tour of the standard accounts of such properties indicates we ought to be extremely pessimistic about naïve realists accommodating KP by accommodating NrKP: natural kinds are hidden essences and artifact kinds are 
relational, extrinsic properties. Thus, $\mathbf{K P}$ is very likely incompatible with naïve realism. What this means is that we have good reasons to think that ${ }^{\mathbf{N r}} \mathbf{K P}$ is false, due to naïve realism's construal of perceptual experience in relational terms and, relatedly, their denial of separatism.

By contrast, representationalists who wish to endorse KP need not be concerned by the 'hidden' nature of natural kinds, nor the relational nature of artifact kinds. In conceiving of perceptual experiences to be separate from the external world, representationalists understand property perception to be a matter of visual experience attributing, rather than detecting, properties. In doing so, the representationalist avoids the naïve realist's difficulties in accommodating KP. For the representationalist, questions about what properties the perceiver experiences are distinct from questions about the nature of the properties in the scene before the perceiver. For, as all parties in the debate recognise: whether a perceiver experiences some property to be instantiated in the scene before them is, on representationalism, a matter that is entirely distinct from the question of whether the property is so instantiated (hence the theory's common-factor nature). But equally, then, whether a perceiver experiences some property to be instantiated in the scene before them must likewise, on this account, be independent of whether that property is instantiated, while being either (i) strictly 'hidden' or (ii) relational. With perceptual experience, on the representationalist account, considered separate from world, facts about the properties themselves within the scope of KP do not matter for the possibility of RepKP in the way they matter for ${ }^{N r} \mathbf{K P}$. Again, even if there are theories of kinds that render them candidates for perceptual detection, to understand $\mathbf{K P}$ in terms of property attribution, rather than property detection, is to tread the path of least resistance: on the representationalist framework, and in line with its commitment to separatism, no theory of the nature of kinds must be assumed to accommodate KP. And the reason for this is simply that $\mathbf{K P}$, on representationalism, is not a matter of being related to actual instances of such properties. KP, then, favours representationalism over naïve realism.

Now, the representationalist needs to give some account of how perceptual experience represents the instantiation of kinds, like 'being water', 'being a doorknob', etc. The typical way they do so is to talk of the activation in perceptual experience of the relevant concepts WATER, DOORKNOB, etc. This is to assume, with Siegel (2006: 486), that kind properties cannot be represented nonconceptually. There are a plethora of further issues here concerning, e.g., concept application, concept acquisition and the nature of concepts themselves. But however these issues get settled, the important point is that the activation of such concepts, e.g., WATER, DOORKNOB, etc., in perceptual experience, will not be analysed as matter of relations to instances of the relevant properties, lest the representationalist threaten commitment to a common-factor theory. To that extent, the representationalist is able to account for the perceptual experience of kind properties, even if such properties are strictly 'hidden', given that such properties are attributed to objects in perception, rather ones that the subject is sensorily related to.

To make this suggestion more concrete, and to illustrate the relevant contrast between naïve realism and representationalism, suppose that antirealism about natural kinds is true. On this view, there are no such properties 'being water', 'being a tomato', etc. It would follow that NrKP is false. There would be no instances of natural kinds to perceptually detect (even supposing natural kind properties would be such candidates, were they to exist). Nevertheless, RepKP could still be true, given the representationalist's commitment to separatism. Perceptual experiences might still attribute kind properties to objects. For instance, perceptual experience might be counterfactually sensitive to the colours and shapes 
of the objects we call tomatoes, doorknobs, etc. thereby activating kind concepts in perception that were learned via ostension. On one model, which appears neutral between realism or antirealism about kinds, this is precisely how KP is brought about (see Siegel 2006 on perceiving pines and Macpherson 2012): plausibly, the visual system has no in-built capacity for perceiving kinds and is not psychophysically sensitive to the instantiation of such properties (hence the problem for naïve realism); so rather than being a 'bottom-up' process, KP is plausibly a matter of top-down influence from the subject's conceptual repertoire.

Granted, in the antirealist situation envisaged above, perceptual experience would be erroneous; objects would not instantiate kind properties because there are none. But such an error-ridden account of KP is no more incoherent than is, say, an error-ridden view of colour perception, no matter its unattractiveness. By contrast, in understanding perceptual experience to be a relation, the naïve realist cannot recognise the possibility of an errorridden theory of $\mathbf{K P}$; for them, $\mathbf{K P}$ entails commitment to the existence of kind properties themselves, whereas for representationalism, KP does not. This shows why one cannot simply assume that the adoption of a representationalist framework over a naïve realist one makes no difference to which properties are perceptually experienced. On naïve realism, the inexistence of properties of type $K$ entails there can be no perceptual experiences of $K$. Not so on representationalism.

Let us take stock: what this means is that someone attracted by $\mathbf{K P}$ ought not to defend naïve realism. For, on that view, there is no KP without having to affirm a theory of such properties on which they are candidates for perceptual detection, rather than hidden essences (in the case of natural kinds) or extrinsic properties (in the case of artifact kinds). Even assuming this can be achieved, representationalism would still be preferred. For on the latter view, with KP understood as a matter of attributing properties to objects (given separatism), no assumptions need to be made about the metaphysics of kinds. Indeed on representationalism, there is the possibility of seeing objects to be tomatoes, doorknobs, guitars, etc. even if there are no such properties 'being a tomato', 'being a doorknob', 'being a guitar', etc. to begin with. This is not so on naïve realism. So representationalism is much less theoretically burdensome than naïve realism, and much more flexible, in terms of its accommodation of $\mathbf{K P}$.

So, contrary to what is usually supposed, KP does have consequences for our metaphysics of perception: one who believes $\mathbf{K P}$ to be true ought not to defend naïve realism. KP favours representationalism. The methodological assumption that one can engage the issue of whether KP is true, independent of whether one is a representationalist or naïve realist, and without altering KP's truth value, is extremely doubtful.

\section{IV - Impure Relationalism}

The solution for the naïve realist who wishes to accommodate $\mathbf{K P}$ is a relatively simple one. They should hold that to perceive an object, e.g., a tomato, as the kind of object it is involves the tokening of two events:

A relational event: one of visually detecting the tomato and its intrinsic, low-level properties, e.g., its redness and roundness. 
A representational event: one of visually representing the instantiation of the natural kind property 'being a tomato.'

On this view, KP factorises into two distinct, or disunified, mental events. The events are distinct insofar as they have differing metaphysical natures. The first is relational; it is an event of detecting a property instance, and so is externally individuated, nonconceptual, and licences existential generalisation. The second is representational; it is an event of attributing a property instance, and so is internally individuated, and fails to licence existential generalisation. Call this view 'impure relationalism.'

Revisiting some of the claims of section I, the relational event should be understood as nonconceptual one. It is a detecting of a particular object and those of its intrinsic properties that can be detected, the latter serving as (one of) the event's relata. The event does not represent the object and its properties; it is a relation of sensory awaress between subject and environment. By contrast, the representational event should, in this context, be understood as a conceptual one, assuming, again, that kind properties are not candidates for being nonconceptually represented. The event is to be analysed as the perceptual attributing of a kind property to the object before one.

Impure relationalism must say how the two events are related. In order for the position to be attractive for naïve realists, the view ought to explain the representational event in terms of the relational event, plus some further factor. Impure relationalism, that is, if it is to be naïverealist-friendly, ought to hold that perceptual detection is more basic than perceptual representation; hence why the view should be dubbed impure relationalism.

Now, the possibility of explaining representational content in terms of perceptual detection is suggested by Logue (forthcoming). But the impure relationalist needs to specify the factor that mediates between perceptual detection and perceptual representation. That factor is most naturally taken to be the subject's conceptual repertoire. The idea is that one visually represents an object to be a tomato by virtue of visually detecting an object's colour and shape, in addition to having one's tomato concept activated, assuming one has such a concept. On this view, KP is not mandatory, but is a matter of what concepts a subject possesses. Two subjects, both looking at a tomato, and who both perceptually experience its colour and shape, may differ experientially.

A view like this is defended by Schellenberg. It is worth contrasting the two. Schellenberg writes:

[I]n virtue of being perceptually related to objects and the properties they instantiate, one represents those very objects and property-instances by employing concepts by means of which one refers to those objects or property-instances. (2011:729)

However, Schellenberg holds that perceptual detection and perceptual representation are mutually dependent. So Schellenberg does not recognise the possibility of a subject's having tokened only the relational event, without the involvement of some concepts, while attributing to the subject an episode of bona fide perceptual contact with the environment. I take it that this is what she affirms in writing that "perceptual relations to the world and the content of experience should be recognized to be mutually dependent in any explanation of what brings about perceptual awareness of the world." (2011: 732) 
According to impure relationalism, by contrast, the relational event is fundamental. In addition, impure relationalism, no less than standard varieties of naïve realism, affirms that the relational event, even taken in isolation, is a genuine perceptual encounter with an object and its properties.

Impure relationalism and Schellenberg's view differ further still insofar as she does not seem to distinguish properties that one is sensorily related to and properties that one represents, holding that the latter just are "those very... property instances" (2011: 729) to which one is related. Impure relationalism, by contrast, is motivated precisely on the grounds that the two seem to come apart. In particular, once one grants $\mathbf{K P}$, and has in the forefront of one's mind key differences between representationalism and naïve realism, one should think that kind properties are potential candidates for perceptual representation, but are unlikely candidates for perceptual detection.

Despite their differences, it should be stressed that impure relationalism and Schellenberg's view are very similar. For both, KP amounts to conceptually mediated perceptual representation, on the basis of bearing sensory relations to one's environment (assuming Schellenberg would wish to affirm KP, which she may not). Impure relationalism is also very close to the 'experience pluralism' that John Bengson defends (2013; see also Bengson et al. 2011). Bengson's view likewise combines relational and conceptual-cum-representational elements. His position is worth highlighting, since he also appears to clash with Schellenberg in affirming that the naïve-realist-like event can occur in isolation, sans the conceptual-cumrepresentational one. In particular, Bengson wants to accommodate cases in which perception detects a property instance but does not attribute it to anything, as when one experiences ('detects') pitch blackness at night, without experiencing ('representing') anything to be black. Impure relationalism also makes room for such cases of property detection without property representation. Schellenberg's view, by contrast, seems unable to accommodate them. Impure relationalism and Bengson's experience pluralism appear to further agree that perceptual detection is, while perceptual representation is not, nonconceptual. Moreover, Bengson et al. (2011: 169 n.10) hold that while the relevant relational event cannot be analysed in terms of the representational event, they speculate that it may be possible to analyse the representational event in terms of the event of perceptual detection, plus concept possession. This possibility is precisely what impure relationalism affirms is so.

Nevertheless, experience pluralism and impure relationalism clash on the matter of KP. As I noted above, Bengson (2013: 805) claims that "[T]he debate over richness looks to be smoothly captured in terms of property-presentation." The central contention of this paper is that this is false (where 'presentation' is a synonym for 'detection' and the richness debate includes debate over KP). Properties that are candidates for being perceptually represented are not automatically candidates for being detected: in fact, kind properties are exceptionally poor candidates for perceptual detection. Bengson's experience pluralism fails to recognise this.

At this point, it is worth contrasting impure relationalism with a naïve realist theory which attempts to accommodate $\mathbf{K P}$ in conceptual terms, while eschewing talk of representational content. Such a view is defended by both William Fish (2009) and Mark Johnston (2006). For instance, in defending KP, Fish (2009: 70) claims that a subject has the capacity to "pick up" the property of something's being a shoe, a computer, etc. (his examples) only if the subject has the concept SHOE, COMPUTER, etc. Relatedly, Johnston claims that: 
Conceptual sophistication helps us to use our senses to mine the scene, or more generally the scenario before the senses, for relevant exemplifications - his bluffing, her raising, your having a busted straight. (2006: 283, emphasis in original)

Someone who is attracted by KP should find this to be unobjectionable. Again, it would be unlikely if the visual system had an in-built sensitivity to something's being a shoe or being a bluff. To that extent, the subject's conceptual repertoire appears a necessary ingredient in KP. This suggests the following reply to my arguments on behalf of the naïve realist: if that ingredient (the subject's concepts) is available to the representationalist to explain the attribution of kind properties of objects, then why should it be unavailable to the naïve realist to explain the detection of kind properties? On either theory, KP can be pictured as a conceptually-informed 'top down' process. On neither view need KP be pictured as a mysterious ‘bottom up' psychophysical sensitivity to hidden essences, intrinsic or relational.

The problem is that Fish's and Johnston's strategy for explaining KP simply dodges the key questions that a naïve realist must answer. First, what is problematic is how possession of the concept SHOE allows one to "pick up" or "mine" the relevant property, given that it is a complex of extrinsic, relational properties, the constituents of which are not in the subject's field of view. Second, the very thing that the naïve realist needs to explain is what "picking up" or "mining" a property, via concept possession, amounts to. On the representationalist account, this matter is straightforward: perceptual experiences are representational events and so can, by their nature, be concept-involving. It is not at all clear what the naïve realist can say to explain the involvement of concepts in perception, given their non-representational analysis of perception. What the naïve realist owes is an account of the commensurability of concepts with perception. What Fish and Johnston offer is the stipulation that the two are so commensurable.

A potential line of response may begin by noting that many naïve realists understand perceptual experience to be a polyadic relation, rather than a simple dyadic one between subject and object (Brewer 2011; Campbell 2009). Indeed Fish (2009) holds that multiple relata are involved in perception: not simply the particulars situated before the subject, but also the perceiver's attentional resources and idiosyncrasies of their visual system. All of these factors are understood by him to be elements that constitutively shape token detection relations of perceptual experience. Talk of 'constitutive shaping' is commonplace among naïve realists (Martin 2004: 64; see also Kalderon 2015: ch.9 for a particularly insightful discussion). So perhaps a naïve realist ought to claim that what concepts a subject possesses, no less than what objects happen to be in the scene before them, how their attention is distributed, etc. plays a constitutive role in determining the 'contours' of perceptual experience. This is how one arrives at the view affirmed by Fish and Johnston.

This is progress, but not much. It remains for the naïve realist to explain how a concept integrates with a non-representational state of perceptual detection. So long as the naïve realist thinks of perceptual experience as non-representational, it is left obscure how concepts fold into perception in the relevant, constitutive manner. For that to be possible, concepts must be commensurate with perception. And talk of concepts being an 'extra relatum' in perceptual experience just takes that commensurability for granted. It does not explain it. The 
relevant questions are left unanswered; in particular, how concepts can be considered relata to begin with. ${ }^{7}$

So, just what it could mean to "pick up" or "mine" a property via the possession of a concept is unexplained on the standard naïve realist account. Representationalists face no such difficulty: perceptual experience is representational and so can, by its nature, be conceptinvolving. At this point, the naïve realist attracted by KP should relent and admit of the need to introduce a representational event. This is a second way in which impure relationalism can be motivated, independent of concerns about the 'hidden' nature of kinds: if concepts are necessary for KP, then the naïve realist is pressured to invoke a representational event to explain how KP is possible.

A final remark about impure relationalism: the view holds that both the relational and representational events in KP are ones with phenomenology. Impure relationalism thus avails itself of both the naïve realist and representationalist accounts of phenomenal character. In other words, a consequence of adopting impure relationalism is that not only is the metaphysics of KP disunified, KP's phenomenology is too. What it is like to perceptually experience those of an object's intrinsic properties that can be so experienced is one thing: nonconceptual, sensory detection. Whereas what it is like to perceptually experience an object's kind properties is another: a conceptual matter of property-attribution. So, a potential objection to impure relationalism is that it fails to respect the phenomenal unity that we find in mature perception: phenomenologically, there doesn't seem to be two distinct events involved in perceiving objects to be the kinds of things they are.

Reflecting on the role that attention plays with respect to each event suggests that there may not be as much unity as initially supposed. Imagine you are looking at the fruit and vegetable aisle of a supermarket. As you distribute your attention over the scene differently, focusing on a single tomato, say, the phenomenal character of your experience changes. What happens in such a case? One thing that plausibly occurs is that the tomato's colour becomes more determinate for you (Nanay 2010). On impure relationalism, this is a case of attention making a difference to the relational, nonconceptual event involved in KP.

There seems no analogous role for attention to play in the case of perceptually attributing kinds. Once one has perceptually attributed to an object the kind property 'being a tomato', changing how one attends to the object does not make that property more determinate. As one focuses attention on the left side of the tomato, say, one gets more determinate information about the colour of the tomato on that side, as well more determinate information about its shape; fissures on the tomato's surface may become more salient, say. This is all independent of the subject's concepts. By contrast, when changing how one attends to the surface, one doesn't thereby get more determinate information about the object's 'tomatoeyness.' One can of course get more determinate information about the type of tomato before one, whether it is plum rather than cherry, say, but this is a matter of what concepts are activated in perception, rather than a matter of how attention is distributed. The overall phenomenology of KP thus combines the phenomenology of perceptual detection with the phenomenology perceptual

7 I pursue this line of argument against naïve realism further still in Cavedon-Taylor ms. 
representation. What it is like for a subject who sees a tomato, absent the concept TOMATO, differs from what it is like for a subject whose TOMATO concept is activated in perception. ${ }^{8}$

\section{V - Conclusion}

This paper has sketched a disunified account of perception I have dubbed 'impure relationalism.' My hope is that I have not engineered an artificial-sounding dialectical situation in order to motivate it. For many of us, it really is plausible that we perceptually experience tomatoes, doorknob, trees, and guitars, to be the very kind of things they in fact are. Or that, in some cases, perception gets its wrong, and we end up seeing things like pieces of wax or soap to be tomatoes or lemons. In this vein, consider Peter Strawson's celebrated claim about how a particular perceptual experience might be described by the ordinary person:

I see the red light of the setting sun filtering through the black and thickly clustered branches of the elms; I see the dappled deer grazing in groups on the vivid green grass. (1979: 97)

Strawson's observation was instrumental in debilitating sense-datum theories, reminding us that "mature sensible experience (in general) presents itself as... immediate consciousness of the existence of things outside us" (Ibid) rather than being as of private mental intermediaries in phenomenal space. But Strawson's claim may also motivate us to affirm KP. What we ordinarily take ourselves to perceive, we not only experience to be external to us; rather, that which we perceive we also experience, on occasions, to be such kinds as elms, deer, grass, etc., and not merely a mosaic of colour and shape.

Equally, many of us feel torn between representationalism and naïve realism. If naïve realism is unlikely to accommodate $\mathbf{K P}$, or, if it can only do so by making certain metaphysical commitments that the representationalist need not, then, for those of us attracted by $\mathbf{K P}$, representationalism is to be preferred, all else being equal. One could give up naïve realism, and side with representationalism. Alternatively, one could adopt the disunified metaphysics of impure relationalism, and thereby reap the benefits that naïve realism is standardly thought to enjoy, e.g., in terms of explaining knowledge of reference (Campbell 2002), the phenomenal particularity of perception (Martin 2002), and so on.

Moreover, although I have restricted my focus to kind properties, there may be other socalled 'high-level' properties that, as metaphysicians, we are anxious about being candidates for perceptual detection, but which we may have epistemic or phenomenological grounds for thinking are perceptually experienced. These properties may include aesthetic properties, causal properties, dispositional properties, mental properties, moral properties, semantic properties, etc. Impure relationalism provides the way out of such a dilemma. But I do want to stress that there seems something important about kind properties, relative to these others, and so something of fundamental importance about KP. This is what Strawson's observation

$8 \quad$ Fulkerson (2014: 47) also appears to affirm some phenomenal disunity between the perceptual experience of kinds and the perceptual experience of more basic, low-level properties. He observes that the former are not feature-bound in the way that the latter are. Fulkerson's explanation similarly appeals to differences in determinacy. 
helps highlight: an ordinary description of perceptual experience is perhaps more likely to include kind-terms than terms for any of the other above properties. For instance, one might reasonably hesitate to defend a particular theory of perception's metaphysics on the basis of considerations surrounding aesthetics properties, say, and their potential candidacy for being perceptually experienced.

Granted, however, there are many for whom impure relationalism will not seem wellmotivated. I have taken KP for granted throughout. But not everyone thinks KP is true. Some deny it, presumably being unmoved by considerations such a Strawson's, holding that we perceive only so-called 'low-level' properties, such as colours, shapes, and perhaps spatial orientations (Brogaard 2013; Price 2009). Moreover, some hold that there is no fact of the matter regarding KP (Logue 2013). Some would be unmoved on different grounds, due to denying there are phenomenal looks to begin with (Martin 2010). Others might want to account for KP in terms of states of seemings, rather than perceptual experiences, narrowly construed (Reiland 2014). And some naïve realists claim that perceptual experience is a matter of detecting objects alone and not their properties (Brewer 2011). But, for those of us attracted by both KP and naïve realism, and for those card-carrying naïve realists who wish to accommodate $\mathbf{K P}$, impure relationalism is a theory worth taking seriously. ${ }^{9}$

\section{References}

Bayne, T. (2009). "Perception and the Reach of Phenomenal Content." Philosophical Quarterly 59 (236): 385-404.

Bloom, P. (2007). "Water as an Artifact Kind." In E. Margolis and S. Laurence (eds.), Creations of the Mind: Theories of Artifacts and Their Representation. Oxford University Press.

Bengson, J. (2013). "Presentation and Content A Critical Study of Susanna Siegel. The Contents of Visual Experience." Noûs 47 (4): 795-807

Bengson, J., Grube, E. and Korman, D. (2011). "A New Framework for Conceptualism." Noûs 45 (1): 167-189.

Brogaard, B. (2013). “Do we Perceive Natural Kind Properties?” Philosophical Studies 162 (1): $35-42$.

(forthcoming). "The Phenomenal Use of 'Look' and the Contents of Perception." Philosophy Compass.

Brewer, B. (2011). Perception and its Objects. Oxford University Press.

$9 \quad$ Thanks to Tim Bayne, Helen Beebee, Laura Gow, Jack Lyons, Clare Mac Cumhaill and Bence Nanay for discussion and helpful suggestions on earlier drafts. My thanks also to the editors for their invaluable feedback. This research was made possible by FWO Odysseus grant G.0020.12N. 
Byrne, A. and Logue, H. (2008). "Either/Or." In A. Haddock \& F. Macpherson (eds.), Disjunctivism: Perception, Action, Knowledge. Oxford University Press.

Campbell, J. (2002). Reference and Consciousness. Oxford University Press.

(2009). "Consciousness and Reference." In B. McLaughlin, A. Beckermann \& S. Walter (eds.), The Oxford Handbook of Philosophy of Mind. Oxford University Press.

Cavedon-Taylor, D. (ms). "Can the Naïve Realist Explain Sensory Integration?" [http://www.academia.edu/8921036/Can_the_Naive_Realist_Explain_Sensory_Integration]

Chisholm, R. (1957). Perceiving: A Philosophical Study. Cornell University Press.

Fish, W. (2009). Perception, Hallucination, and Illusion. Oxford University Press.

----------. (2010). Philosophy of Perception: A Contemporary Introduction. Routledge.

Fulkerson, M. (2014). The First Sense: A Philosophical Study of Human Touch. MIT Press.

Genone, J. (2011). "Review of Susanna Siegel's The Contents of Visual Experience." Notre Dame Philosophical Reviews [https://ndpr.nd.edu/news/24721-the-contents-of-visualexperience/]

Jackson, F. (1977). Perception: A Representative Theory. Cambridge University Press.

Johnston, M. (2004). "The Obscure Object of Hallucination." Philosophical Studies 120 (13): 113-83.

(2006). "Better Than Mere Knowledge? The Function of Sensory Awareness." In T. Gendler and J. Hawthorne (eds.), Perceptual Experience. Oxford University Press.

Kalderon, M. (2015). Form without Matter: Empedocles and Aristotle on Color Perception. Oxford University Press.

Kennedy, M. (2009). "Heirs of Nothing: The Implications of Transparency." Philosophy and Phenomenological Research 79 (3): 574-604.

Kripke, S. (1972). "Naming and Necessity." In G. Harman \& D. Davidson (eds.), Semantics of Natural Language. Reidel.

Logue, H. (2013). "Visual Experience of Natural Kind Properties: Is There Any Fact of the Matter?” Philosophical Studies 162 (1): 1-12.

(forthcoming). "Experiential Content and Naive Realism: A Reconciliation." In B. Brogaard (ed.), Does Perception Have Content? Oxford University Press.

Lyons, J. (2005). “Clades, Capgras and Perceptual Kinds.” Philosophical Topics 33 (1): 185206. 
(2009). Perception and Basic Beliefs: Zombies, Modules, and the Problem of the External World. Oxford University Press.

Macpherson (2012). "Cognitive Penetration of Colour Experience: Rethinking the Issue in Light of an Indirect Mechanism." Philosophy and Phenomenological Research 84 (1): 24-62.

Martin, M. (2002). "Particular Thoughts and Singular Thought." In A. O'Hear (ed.), Logic, Thought and Language. Cambridge University Press.

(2004). “The Limits of Self-Awareness.” Philosophical Studies 120 (1-3): 37-89.

(2010). "What's in a Look?" In B. Nanay (ed.) Perceiving the World. Oxford University Press.

Nanay, B. (2010). “Attention and Perceptual Content.” Analysis 70 (2): 263-270.

(2013). Between Perception and Action. Oxford University Press.

Noë, A. (2005). “Real Presence.” Philosophical Topics 33 (1): 235-264.

Price, R. (2009). "Aspect-Switching and Visual Phenomenal Character." Philosophical Quarterly 59 (236): 508-518.

Putnam, H. (1973). “Meaning and Reference.” Journal of Philosophy 70 (19): 699-711.

(1999). The Threefold Cord: Mind, Body and World. Columbia University Press.

Reiland, I. (2014). “On Experiencing High-Level Properties." American Philosophical Quarterly 51 (3): 177-187.

Schellenberg, S. (2011). "Perceptual Content Defended.” Noûs 45 (4): 714 -750.

Siegel, S. (2006). "Which Properties are Represented in Perception?" In T. Gendler \& J. Hawthorne (eds.), Perceptual Experience. Oxford University Press.

(2010). The Contents of Visual Experience. Oxford University Press.

Silins, N. (2013). "The Significance of High Level Content.” Philosophical Studies 162 (1): 13-33.

Strawson, P. (1979). "Perception and Its Objects." In G. Macdonald (ed.), Perception and Identity: Essays Presented to A. J. Ayer with His Replies. Macmillan; page references refer to reprint in A. Noë and E. Thompson (eds.) (2002). Vision and Mind: Selected Readings in the Philosophy of Perception. MIT Press.

Thomasson, A. (2003). "Realism and Human Kinds." Philosophy and Phenomenological Research 67 (3): 580-609.

Travis, C. (2004) “The Silence of the Senses.” Mind 113 (449): 57-94. 
Tye, M. (1995). Ten Problems of Consciousness: A Representational Theory of the Phenomenal Mind. MIT Press.

Wiggins, D. (2001). Sameness and Substance Renewed. Cambridge University Press. 